\title{
Characterising African tick communities at a wild-domestic interface using repeated sampling protocols and models
}

\author{
Eve Miguel $^{\mathrm{a}, \mathrm{b}, \mathrm{c}, *}$, Thierry Boulinier ${ }^{\mathrm{b}}$, Michel de Garine-Wichatitsky ${ }^{\mathrm{a}, \mathrm{c}}$, \\ Alexandre Caron ${ }^{\mathrm{a}, \mathrm{c}, \mathrm{d}}$, Hervé Fritz ${ }^{\mathrm{e}}$, Vladimir Grosbois ${ }^{\mathrm{a}}$ \\ a Cirad-ES,AGIRs, (Animal et Gestion Intégrée des Risques/Animal and Integrated Risk Management), Montpellier, France \\ ${ }^{\mathrm{b}}$ CNRS-Centre d'Ecologie Fonctionnelle et Evolutive - UMR 5175, Montpellier, France \\ ${ }^{c}$ Cirad-ES, AGIRs-RP-PCP, Harare P.O. Box 1378, Zimbabwe \\ d Mammal Research Institute, University of Pretoria, Pretoria, South Africa \\ e CNRS-Laboratoire de Biométrie et Biologie Evolutive UMR 5558, UCB Lyon Villeurbanne, France
}

A b s t r a c t

The sharing of habitat by wild and domestic animals may result in pathogen transmission, notably via ectoparasite vectors such as ticks. Interfaces between protected and communal lands constitute sharp transitions between areas occupied by host communities that are extremely contrasted in terms of com-position, diversity and density. Empirical characterizations of tick communities and of their vertebrate hosts are strongly relevant for understanding the mechanisms leading to disease transmission between wild and domestic animals. In the present study we aimed at depicting the pattern of spatial variation in the density of immature ticks at such an interface located in Zimbabwe. At the end of the 2011 rainy season, we applied a hierarchical repeated protocol to collect ticks. We used the dragsampling method in the vegetation surrounding water pans used by ungulates in 3 distinct landscape compartments (i.e. national park, mixed compartment and communal lands) characterized by a differential use by wild and domestic hosts. We combined generalized linear mixed models with site occupancy models to (1) assess tick aggregation levels at different spatial scales, (2) identify and disentangle factors which influence the density and probability of tick detection, and (3) compare robust estimations of tick densities among the landscape compartments. Ticks belonging to the Amblyomma and Riphicephalus genuses were found to be the most abundant. At small scale, ticks were more often detected in the afternoon and were more abun-dant close to water pans for Amblyomma and Riphicephalus genuses. Riphicephalus spp. density was also higher in grassland and bushland vegetation types as compared to woodland vegetation type. At large scale, for the three detected genuses, density was much higher near water pans located in the communal lands as compared to the national park and mixed compartment. Given that host community's diversity is much lower in the communal areas than in the two other landscape compartments, these results are compatible with a dilution effect but not sufficient to demonstrate this effect without additional studies. Up to date, it is the first utilization of these rigorous sampling and statistical modelling methodologies to estimate tick density in African ecosystem simultaneously at large and small scales.

Keywords:

Africa ; Aggregation; Drag sampling; Host diversity; Site occupancy modelling

\section{Introduction}

The growth of global human population and of per capita consumption has led over the last fifty years to an important increase in

\footnotetext{
* Corresponding author at: Cirad AGIRs - Animal et Gestion Intégrée des Risques TA C 22/E Campus International de Baillarguet - 34398 Montpellier cedex 5 France. Tel.: +330 4675939 74; fax: +330467593754.

E-mail addresses: eve.miguel@cirad.fr, eve.miguel@gmail.com (E. Miguel).
}

the total area dedicated to the production of agricultural products in developing countries (Green et al., 2005; Gibbs et al., 2010). At the same time, concerns about the erosion of natural ecosystems and of biodiversity have motivated the creation and the expansion of protection areas for nature conservation with the support of integrated conservation and rural development investment made by national governments and international donor agencies (Wittemyer et al., 2008). These trends in land use and conservation and development policies have resulted in the fast growth of human and livestock populations living at the edge of wildlife protection areas in Africa and Latin America (Wittemyer et al., 2008). 
The situation of Southern Africa where the creation of Transfrontier Conservation Areas is currently ongoing is emblematic of this phenomenon and requires addressing the coexistence of rural communities and wildlife (Anderson et al., 2012). Such coexistence is problematic because the direct or indirect interactions among wild animals, domestic animals and humans resulting from the exploitation of the same habitats and resources generate a number of conflicting interferences including competition for pasture and water (e.g. Baudron et al., 2011), crop damages (e.g. Guerbois et al., 2012), predation of livestock (e.g. Butler, 2000) and transmission of infectious diseases between wildlife, livestock and humans (e.g. Miguel et al., 2013). Many livestock diseases such as foot-andmouth disease, bovine tuberculosis, brucellosis, rift valley fever and theileriosis circulate at interfaces between communal lands and protected areas in Southern Africa. Their possible maintenance in wildlife populations could compromise their control in livestock through standard veterinary measures such as vaccination and dipping against tick-borne diseases (Caron et al., 2013). In addition some of these pathogens such as brucellosis, rift valley fever or bovine tuberculosis are zoonotic. As a consequence they also put local human populations at risk of outbreaks and, because human populations are globally connected, they also represent a global public health concern (Jones et al., 2013). Understanding the mechanisms of pathogen transmission at interfaces between communal and conservation areas is crucial to address these local and global risks.

Wild and domestic ungulates can be hosts for the adult and for the immature stages of the 3 tick genus commonly detected in austral Africa, Rhipicephalus spp.; Hyalomma spp. and Amblyomma spp. (Table 1a) (Walker et al., 2013) and several pathogens infecting livestock and wild ruminants in Southern Africa are transmitted by such ticks. For instance the protozoan Theileria parvas is the causative agent of Theleriosis and is mainly transmitted by Rhipicephalus appendiculatus and $R$. zambeziensis ticks (Latif et al., 2002) while the bacterium rickettsia Cowdria ruminantium is the causative agent of Heartwater and is transmitted by Amblyomma spp. ticks (Uilenberg et al., 1993). Empirical characterizations of communities of ticks and identification of the biotic and abiotic factors influencing their composition and density at interfaces between protected and communal lands is thus strongly relevant for understanding the mechanisms leading to disease transmission between wild and domestic animals. Moreover, at these interfaces host diversity varies sharply over short distances with wild host communities being usually more diverse than domestic host communities, while abiotic factors such as meteorological conditions or soil composition are relatively homogeneous. Investigations of tick communities at such interfaces can thus provide insights on the influence of host diversity on parasite abundance; a relevant topic regarding health regulatory functions of biodiversity and natural ecosystems (Hails and Ormerod, 2013).

However, investigations of the distribution of parasites such as ticks can be hampered by low and heterogeneous detection probabilities (McClintock et al., 2010) implying that observed counts are biased estimations of true abundances (Royle et al., 2005). It is thus crucial to use sampling strategies and analytical approaches that minimize these biases. Field protocols where sites or hosts are repeatedly sampled within short time periods (Bailey et al., 2004) and statistical models specifically designed to be fitted to the resulting data allow simultaneous estimation of detection probabilities and abundance (MacKenzie, 2005; Mackenzie and Royle, 2005). Such methods have however been rarely used so far in disease ecology studies (McClintock et al., 2010; Restif et al., 2012). Another characteristic of parasites such as ticks is that their distribution on hosts or in the environment is often aggregated (Boulinier et al., 1996; Elston et al., 2001), which can have significant implications for the estimations of parameters of populations and communities (Petney et al., 1990).

In the present study we investigated tick densities at an interface between protected and communal lands in Zimbabwe. We implemented a hierarchical repeated tick sampling protocol in three landscape compartments located respectively on the communal side occupied almost exclusively by domestic ungulates, on the protected side occupied exclusively by wild ungulates and on the transition zone between these two sides which is used both by wild and domestic ungulates (hereafter referred to as "mixed compartment"). We combined generalized linear mixed models with site occupancy models to (1) assess tick aggregations at different spatial scales, (2) identify and disentangle the factors which influence the density or the probability of detections of ticks, and (3) compare robust estimations of tick densities in the different landscape compartments.

\section{Materials and methods}

\subsection{Study areas}

The study was carried out in Hwange National Park (HNP), Zimbabwe (35 K 484826E; 794130S) and adjacent communal lands. HNP and its surroundings are characterized by a dry savannah ecosystem where water is a key resource for all vertebrate populations (Valeix, 2011). Three tick sampling compartments were defined (Fig. 1): inside the national park where wildlife is protected and only wild ungulate hosts occur (i.e. Main Camp area); in the mixed compartment between communal lands and the national park where both wild and domestic ungulate hosts co-occur (i.e. Chezhou and Mabale); and in communal lands located relatively far away from the national park (i.e. $30-40 \mathrm{~km}$ : Tinde) where almost exclusively domestic ungulate hosts occur. The mixed compartment is characterized by a mixture of land uses and a large diversity of ungulates (domestic and wild) that are potential tick hosts. Altitude in the area is around $1100 \mathrm{~m}$ and the rainfall is slightly below $600 \mathrm{~mm}$ per year (see word.climate.com). The seasonal climatic pattern is characterized by a rainy season from midNovember to March followed by a cold dry season between April and July and a hot dry season from August to mid-November (see world.climate.com). Vegetation consists in a woodland-bushland savanna dominated by Colophospermum mopane, Combretum spp., Acacia spp. and Baikiaea spp.d (Rogers, 1993). Water pans constitute the main surface water and are scattered over the landscape inside and outside the national park. Water pans density is higher inside the national park, with 0.25 water pans per $\mathrm{km}^{2}$ (in the area of interest) (Valeix, 2011), than in the mixed compartment, with 0.08 water pans per $\mathrm{km}^{2}$ (personal census of water pans and boreholes). Although no water pan density estimation is available for the Tinde communal land, we are aware of several water pans available for domestic hosts in this area. Human activities in the communal areas essentially consist in subsistence farming with small-scale livestock production. Small herds are bred extensively with on average 12 heads of cattle and small ruminants (goats and a few sheep) per herd (Department of Veterinary Services, Cross Dete, Zimbabwe, 2011). Cattle were treated during our study period with an acaricide (Amitraz diluted in pools called 'diptank') at the following frequencies: 4 times/month from January to March, 2 times/month from April to September, one time/month in October and November and 3 times in December. The rainy season was identified by the local veterinary services as the most risky in terms of tick infestation.

Wildlife abundance and diversity inside Hwange National Park are relatively high (see data in Fig. 1 for the beginning of the dry season - confidence intervals are provided in (Chamaille-Jammes et al., 2009)). Livestock diversity and abundance were estimated using 
Table 1

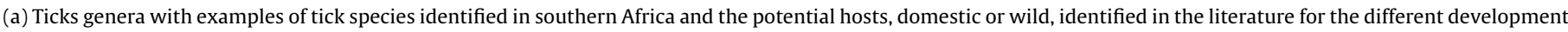
stages of these tick species (Walker et al., 2013).

\begin{tabular}{|c|c|c|c|c|c|}
\hline Genus & Tick species examples & Stage & Hosts & Stage & Hosts \\
\hline Rhipicephalus spp. & $\begin{array}{l}\text { Rhipicephalus simus, Rhipicephalus } \\
\text { zambeziensis;Rhipicephalus evertsi evertsi; } \\
\text { Rhipicephalus appendiculatus; Rhipicephalus } \\
\text { (Boophilus) microplus; Rhipicephalus } \\
\text { (Boophilus) decoloratus }\end{array}$ & Adult stage & $\begin{array}{l}\text { DOMESTIC: Cattle + } \\
\text { Goat, Sheep WILD:Wild } \\
\text { ungulates Buffalo, } \\
\text { Kudu, Zebra }\end{array}$ & Immature stage & $\begin{array}{l}\text { DOMESTIC: Cattle + } \\
\text { Sheep + WILD: Wild } \\
\text { ungulates }\end{array}$ \\
\hline Amblyomma spp. & $\begin{array}{l}\text { Amblyomma variagatum; Amblyomma } \\
\text { hebraeum }\end{array}$ & Adult stage & $\begin{array}{l}\text { DOMESTIC: Cattle, } \\
\text { Goat, Sheep WILD: } \\
\text { Buffalo, Giraffe, Large } \\
\text { ungulates }\end{array}$ & Immature stage & $\begin{array}{l}\text { DOMESTIC: Cattle, } \\
\text { ruminants WILD: } \\
\text { Buffalo, Giraffe, Small } \\
\text { ungulates, Guineafowls }\end{array}$ \\
\hline Hyalomma spp. & $\begin{array}{l}\text { Hyalomma marginatum rufipes; Hyalomma } \\
\text { truncatum }\end{array}$ & Adult stage & $\begin{array}{l}\text { DOMESTIC: Cattle, } \\
\text { Goat, Sheep WILD: } \\
\text { Wild ungulates }\end{array}$ & Immature stage & $\begin{array}{l}\text { DOMESTIC \& WILD: } \\
\text { rodents, small } \\
\text { mammals }\end{array}$ \\
\hline
\end{tabular}

(b) Water pans names and host relative abundance

\begin{tabular}{|c|c|c|c|}
\hline Landscapecompartments & Water pans names & $N^{\circ}$ & Host relative abundance \\
\hline National park & Guvalala & 1 & Wildlife +++ \\
\hline National park & Nyamandhlovu & 2 & Wildlife +++ \\
\hline National park & Makwa & 3 & Wildlife +++ \\
\hline National park & Bala-bala & 4 & Wildlife +++ \\
\hline Mixed & Mataka & 5 & Wildlife ++ \\
\hline Mixed & Mabale & 6 & Wildlife ++/Domestic ++ \\
\hline Mixed & Mabenje & 7 & Wildlife+ Domestic +++ \\
\hline Communal lands & Tinde1 & 8 & Domestic +++ \\
\hline Communal lands & Tinde2 & 9 & Domestic +++ \\
\hline Communal lands & Tinde3 & 10 & Domestic +++ \\
\hline
\end{tabular}

official data collected by the veterinary services for animals referenced at the diptanks (see also Fig. 1 for data from Animal Health Centers, Cross Dete and Tinde, 2011). Ungulate diversity inside the national park (with 11 dominant species) and in the mixed compartment (with a mix of wild and domestic ungulates) is higher than in communal lands (with 5 dominant species). On the other hand, total ungulate density is estimated to be slightly higher on the domestic side (Fig. 1).

\subsection{Tick sampling and identification}

Data on tick density in the vegetation were obtained using the 'drag sampling' method (Short and Norval, 1981; Talleklint-Eisen and Lane, 2000), which consists in dragging a one meter cloth in the vegetation along transects of known length and counting the number of ticks that attached on the cloth. This method is considered efficient for sampling ticks that climb the vegetation and passively await passing hosts. It is considered efficient for sampling host seeking larvae of Amblyomma spp. ticks and host seeking individuals of any stage for most Rhipicephalus spp. (Norval et al., 1992). It is however believed to be inefficient for sampling Hyalomma spp. ticks which remain concealed in favourable micro-habitats and display an active host seeking behaviour (Norval et al., 1992). It has been used to assess tick diversity and density in areas under various land-uses in southern Africa, including protected areas and mixed wildlife-livestock ranches (De Garine-Wichatitsky et al., 1999; Minshull and Norval, 1982; Spickett et al., 1995).

A series of sites was sampled in each of the three landscape compartments during March and April 2011, at the transition between the rainy season and the cold dry season when Amblyomma spp. and Rhipicephalus spp. populations are dominated by the adult and the larval stages (Norval et al., 1992). For maximizing the probability of detecting ticks, sampling was undertaken on the vegetation around water pans where hosts frequently congregate (Fig. 1 and (Zengeya et al., 2011) for domestic animals and (Valeix, 2011) for wild animals). Following recommendations of Royle and MacKenzie (Mackenzie and Royle, 2005; Royle et al., 2005), we adopted a large ratio of number of sampling replicates to number of pans (Fig. 2). Four pans were sampled inside the national park, 3 in the mixed compartment and 3 in communal lands (Table $1 \mathrm{~b}$ and Fig. 1). Within each pan, 8 blocks were repeatedly sampled. Four of these blocks were located at each cardinal direction relatively to the water body (North/South/East/West) within a 50-100 meters radius from the water and the four others within a 0-50 meters radius from the water (i.e bands). Each block was thus $50 \mathrm{~m}$ wide. The flag was dragged in each block along three distinct tracks, back and forth. Furthermore, each track was sampled in the morning and in the afternoon. To sum up, for each of the 10 pans we sampled 8 blocks, varying in terms of distance to water (i.e. band) and cardinal orientation relatively to the water body, four times (back and forth in the morning and in the afternoon) and along three distinct tracks (Fig. 2a). For each block, the vegetation structure was classified in one of the following categories according to the classification proposed by Valeix in 2007 in this type of ecosystem (Valeix et al., 2007b): grassland (G), grass-bushland (GB), grass-woodland (GW), grass-bush-woodland (GBW), bushland (B).

Ticks samples were preserved in $70 \%$ alcohol for later identification at the Tick Research Unit of the Central Veterinary laboratory in Harare by a laboratory technician with extensive experience in tick identification. Because most ticks collected were immature stages (98.5\% were larvae), the identification was performed accurately only to the genus level.

\subsection{Statistical modelling for tick density estimations}

The tick detection data were analyzed using two statistical modelling methods in order to address two specific statistical issues: (1) tick distribution in the environment is likely to be highly aggregated, and (2) the probability of detection of individual ticks may vary due to combined effects of several factors. In order to explore the scales at which tick counts varied, the data were analyzed using a variance component approach. To disentangle density variation from variations in detection probability, site occupancy models were used. 


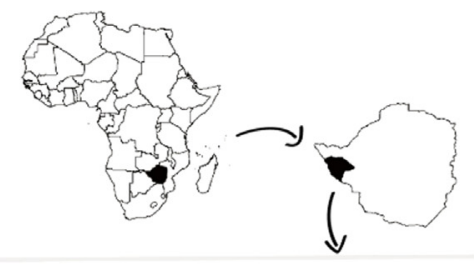

Communal lands
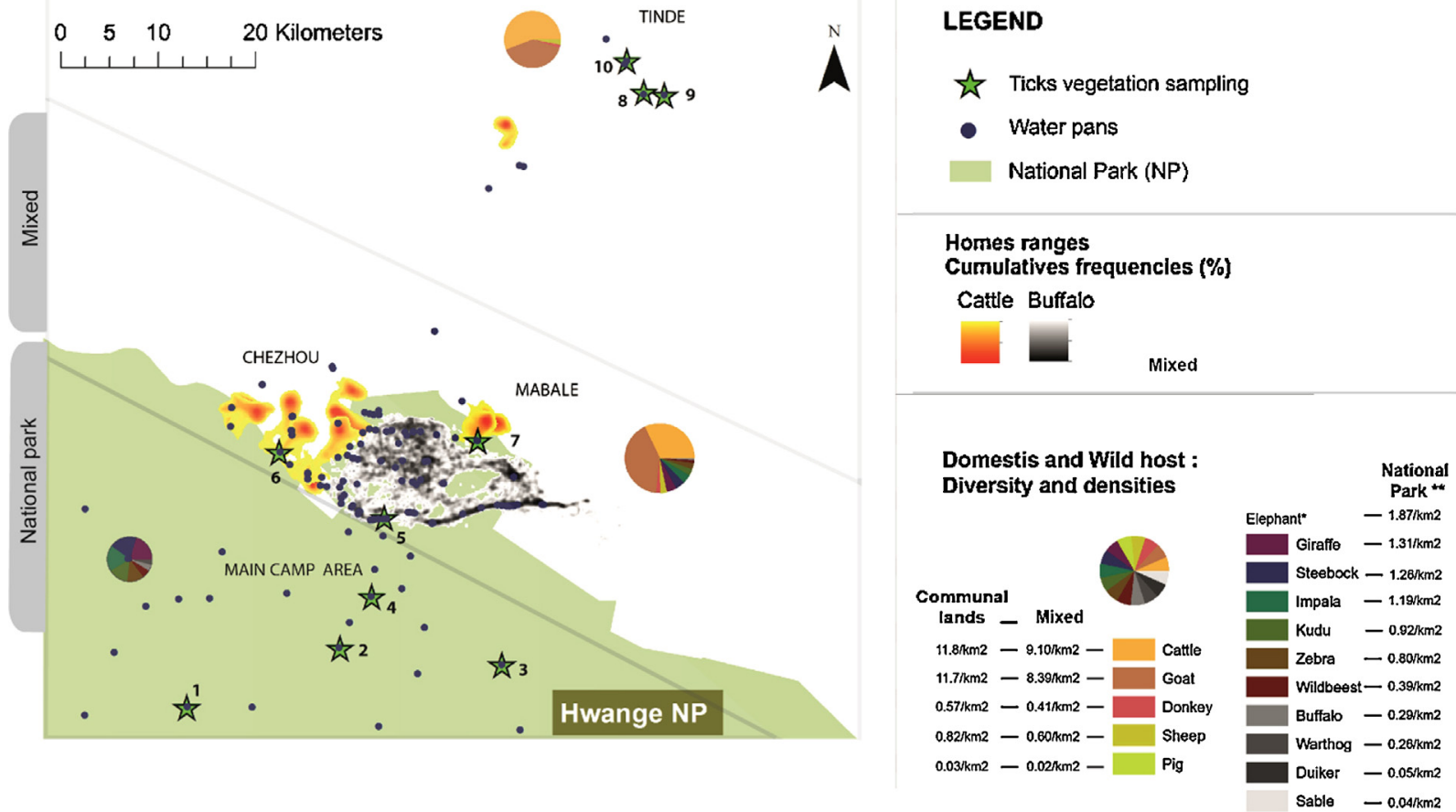

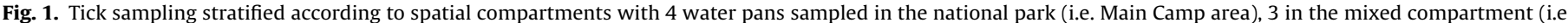

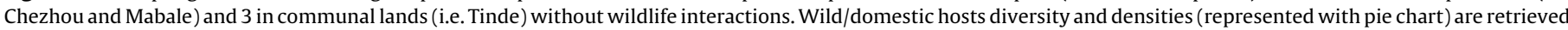

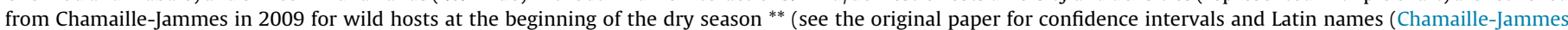

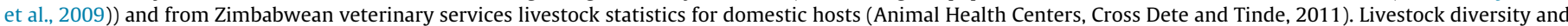

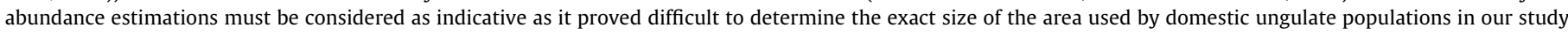
sites. Elephant sp. ${ }^{*}$ is not represented in the pie chart because this species is not considered as a potential host for ticks (see Table 1a and (Walker et al., 2013)).

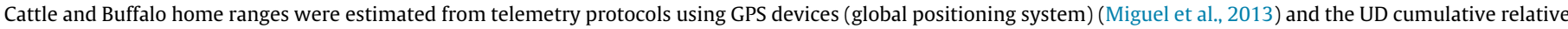
frequencies up to 95\%: the value attributed to a given percentage, $\mathrm{p}$, applies to the area comprised between p and p - 5\% isopleths (see Appendix B for more details).

\subsubsection{Variance estimations to depict tick aggregation patterns}

For each tick genus, a generalized linear mixed model where the number of sampled ticks was the Poison distributed response variable was fitted to the sampling data (Fig. 2b). Random effects were included in the models to estimate the variance in the number of detected ticks at different spatial scales. The random effects considered were landscape compartment, pan (nested in landscape compartment), block (nested in pan) and transects (nested in block). The fixed part of the model included only an intercept term. Analyses were performed using the glmer function in the lme4 package of the $\mathrm{R}$ software ( $\mathrm{R}$ Development Core Team 2011). a)

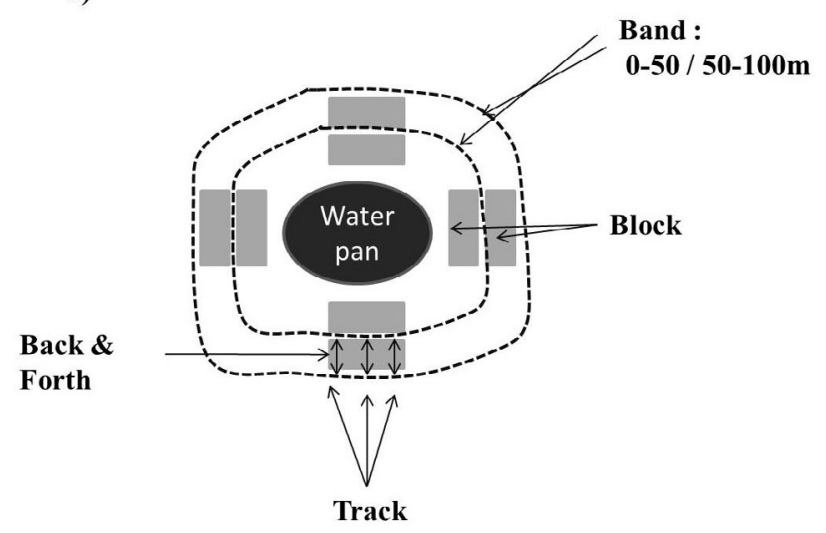

b)

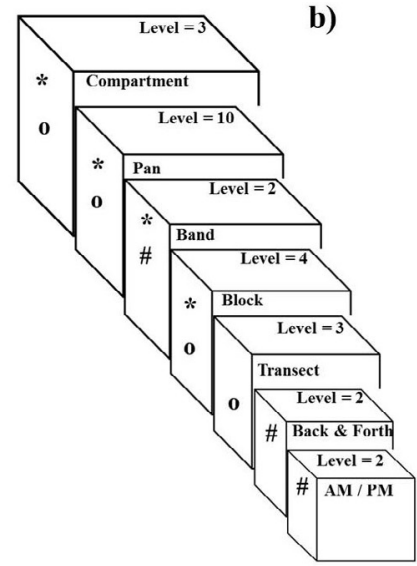

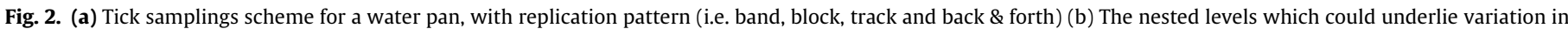

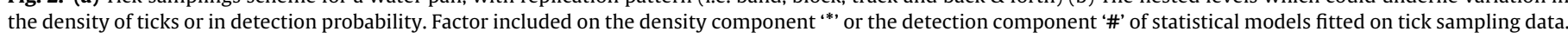
Factors included as random effect 'o' in variance component models to explore aggregation levels. 


\subsubsection{Statistical models for inferring tick density variations while accounting for the detection process}

So-called "occupancy models" were fitted to the repeated count data to disentangle the factors influencing density of ticks from those influencing tick detection probabilities and to obtain estimations of tick densities accounting for variation in detection probabilities. A distinct analysis was undertaken for each tick genus.

2.3.2.1. Models for the estimation of density and detection probabilities. We applied the statistical model developed by Royle and Nichols (2003) for estimating abundance or density from data when individual detection probability is less than 1 . This model applies to data obtained by repeatedly counting over a short period of time a focal organism on a number of sites. We considered each block as a distinct site (s) on which ticks were counted at $R=12$ occasions ( 3 tracks $\times 2$ directions $\times 2$ times of day) by dragging the flag along a 50 meters long track. The count $y_{\mathrm{sr}}(s=1,2, \ldots S ; r=1,2, \ldots R)$ can be viewed as a realization of a binomial process of parameters $N_{\mathrm{S}}$ (local abundance at site $s$ ) and $p_{\mathrm{sr}}$ (individual detection probability at site $s$ for replicate r): $y_{\mathrm{sr}} \sim \operatorname{Bin}\left(N_{\mathrm{s}}, p_{\mathrm{sr}}\right)$. The local abundance, $N_{\mathrm{s}}$, at given site $\mathrm{s}$, is constant over replicated samples, which implies that local density is constant over the survey period and is assumed to be a realization of a Poisson process of parameter $\lambda_{s}, N_{\mathrm{s}} \sim$ Poisson $\left(\lambda_{s}\right)$. Variation in $p_{\text {sr }}$ and $\lambda_{s}$ according to covariates can be specified through logit- and log-linear relationships, respectively. Royle and collaborators (Royle et al., 2005) describe in details the integrated likelihood approach that yields parameter estimates for these models. Underlying assumptions are (i) no change in density in any of the sites considered over the duration of the survey, (ii) no false detection of the focal organism (iii) detecting the focal organism on a given site is independent of detecting it on all the other sites, and (iv) individuals of the focal organism are randomly distributed within sites.

2.3.2.2. Covariates underlying variation in tick density, and detection probabilities. It was considered that tick density could vary according to landscape compartment (national park, mixed, communal land), water pan, distance to the water body ( $0-50 \mathrm{~m}$ or $50-100 \mathrm{~m})$, and vegetation type associated with the block.

The covariates taken into account for modelling variation in detection probability were time of day (morning versus afternoon), cardinal direction, direction of the track dragging (forth or back) and vegetation type in the block. The direction of the track dragging is especially important as the attachment of questing ticks to the flag is likely to lead to a lower probability of detecting individual ticks after the flag has been dragged once on the track.

The density models described above were fitted independently for Amblyomma spp. ticks and for Rhipicephalus spp. ticks using the software PRESENCE (Hines, 2006). For each of these two tick genus, alternative models including distinct sets of explanatory covariates were compared using the Akaike Information Criterion (Burnham and Anderson, 2002). Note that given the considered covariates, the lowest level at which abundance or occupancy could vary was the block and the lowest level at which detection probability could vary was the track sampling replicate.

\subsection{Hosts Shannon index}

In order to explore a potential association between local tick density and diversity of ungulate host community, hosts Shannon index was computed for each landscape compartment. This index took into account the density and diversity of ungulate hosts (Fig. 1) (Logiudice et al., 2008; Lyashevska and Farnsworth, 2012).
Table 2

Variance components analysis of the logarithm of tick counts.

\begin{tabular}{lll}
\hline Species & Rhipicephalus spp. & Amblyomma spp. \\
\hline Variance components & Variance in the log & Variance in the log \\
& of tick counts & of tick counts \\
Transect (nested in block) & 2.57 & 1.28 \\
Block (nested in pan) & 0.17 & 0.60 \\
Pan (nested in compartment) & 2.18 & 1.06 \\
Compartment & 3.23 & 2.77 \\
\hline
\end{tabular}

Estimations of ticks were plotted against hosts Shannon indices (see appendix A for more details on Shannon index computation).

\section{Results}

\subsection{Tick taxa identified}

A total of 713 ticks were sampled and identified from a total of 960 drag-sampling transects. All but 10 of these ticks were immature stages and could only be identified at the genus level. Rhipicephalus spp., Amblyomma spp. and Hyalomma spp. immature ticks were identified. More precisely, for Rhipicephalus spp., 234 immature ticks were sampled in communal lands, 4 in the mixed compartment and 14 in the national park; for Amblyomma spp., 327 immature ticks were sampled in communal lands, 21 in the mixed compartment and 5 in national park, and for Hyalomma spp., 96 immature ticks were sampled in communal lands (among which 65 and 20 in two drag sampling replicates), 2 in the mixed compartment and 10 in the national park. 10 adult ticks were detected in communal lands and identified as Rhipicephalus pravus, $R$. sanguineus and $R$. zambeziensis.

Because the drag sampling method is considered as inappropriate for Hyalomma spp. ticks (see above) and because the counting data suggested that their distribution was highly aggregated (with almost all 96 individuals detected on 2 out of 960 drag-sampling transect replicates) which clearly violates the assumption of random distribution of the focal organism within sites (see above), we did not analyse further the Hyalomma repeated counting data.

\subsection{Modelling}

\subsubsection{Variation at different spatial scales in the number of ticks sampled}

The variance component analysis for the number of ticks sampled revealed the same pattern for Amblyomma spp. and Rhipicephalus spp. ticks. Tick counts varied the most widely at the largest spatial scales: between landscape compartments and to a lesser extent between pans within compartments (Table 2 ). Tick variance at the finest spatial scale (between transects within blocks) was also large (as large as between pans within compartments). At the intermediate spatial scale (between blocks within pans) variance was small (Table 2).

\subsubsection{Statistical models for inferring density variation while accounting for the detection process}

3.2.2.1. Rhipicephalus spp. and Amblyomma spp. detection probability. The models selected for both Rhipicephalus spp. and Amblyomma spp. (Tables 3a and4a) included the time of the day and the forth/back effects on detection probabilities. The probabilities of detecting an individual tick present on the sampling transect during a drag sampling replicate was estimated around 0.01-0.02. Detection probability was lower in the morning than in the afternoon and, as expected, was higher on forth sampling replicates than on back sampling replicates (Tables $3 \mathrm{~b}$ and $4 \mathrm{~b}$ and Fig. 3). 
Table 3

Rhipicephalus spp.: Modelling of detection probability and density.

\begin{tabular}{|c|c|c|c|c|}
\hline \multicolumn{5}{|l|}{ a) Model selection } \\
\hline Density (with intercept) & Detection (with intercept) & AIC & Delta AIC & no. Par. \\
\hline Pan + Veg + Dist to water & AM/PM + Forth/Back & 1290.01 & 0 & 18 \\
\hline Pan + Veg & $\mathrm{AM} / \mathrm{PM}+$ Forth/Back & 1310.18 & 20.17 & 17 \\
\hline Pan + Veg & $\mathrm{AM} / \mathrm{PM}+$ Forth$/$ Back + Band & 1310.57 & 20.55 & 18 \\
\hline Pan + Veg & Forth/Back & 1310.9 & 20.89 & 16 \\
\hline Pan + Veg & $\mathrm{AM} / \mathrm{PM}$ & 1317.49 & 27.48 & 16 \\
\hline Pan + Veg & Constant & 1319.23 & 29.22 & 15 \\
\hline Compartment + Veg + Dist to water & AM/PM + Forth/Back & 1324.23 & 34.22 & 11 \\
\hline Pan + Dist to water & $\mathrm{AM} / \mathrm{PM}$ & 1341.5 & 51.49 & 13 \\
\hline Compartment +Veg & $\mathrm{AM} / \mathrm{PM}+$ Forth/Back & 1346.1 & 56.08 & 10 \\
\hline Pan & AM/PM + Forth/Back & 1355.48 & 65.47 & 13 \\
\hline Pan & $\mathrm{AM} / \mathrm{PM}$ & 1362.74 & 72.73 & 12 \\
\hline Compartment & $\mathrm{AM} / \mathrm{PM}$ & 1391.33 & 101.32 & 5 \\
\hline Veg & $\mathrm{AM} / \mathrm{PM}+$ Forth/Back & 1502.23 & 212.22 & 8 \\
\hline Vegetation & AM/PM & 1509.56 & 219.55 & 7 \\
\hline Dipping & $\mathrm{AM} / \mathrm{PM}$ & 1658.09 & 368.08 & 4 \\
\hline Direction & $\mathrm{AM} / \mathrm{PM}$ & 1735.86 & 445.85 & 6 \\
\hline Dist to water & $\mathrm{AM} / \mathrm{PM}$ & 1771.16 & 481.15 & 4 \\
\hline Constant & $\mathrm{AM} / \mathrm{PM}+$ Forth/Back & 1787.07 & 497.06 & 4 \\
\hline \multicolumn{5}{|l|}{ b) Estimates Rhipicephalus spp. } \\
\hline Rhipicephalus spp. & \multicolumn{2}{|l|}{ Parameter } & Estimate & $95 \% \mathrm{CI}$ \\
\hline Reference for $\mathrm{p}$ (PM, way back) & \multicolumn{2}{|c|}{$\mathrm{p}$ (probability of detecting an individual tick on a dragging replicate) } & 0.013 & {$[0.009 ; 0.018]$} \\
\hline Contrast AM/PM & \multicolumn{2}{|c|}{$\mathrm{OR}(\mathrm{AM} / \mathrm{PM})$} & 0.81 & {$[0.63 ; 1.05]$} \\
\hline Contrast forth/back & \multicolumn{2}{|l|}{ OR (forth/back) } & 1.48 & {$[1.14 ; 1.91]$} \\
\hline Reference for $\lambda$ (Tinde 3 , Grass, $50-100 \mathrm{~m}$ to water) & \multicolumn{2}{|c|}{ Lambda (mean number of ticks on a $50 \mathrm{~m}^{2}$ transect) } & 49.40 & {$[22 ; 110]$} \\
\hline \multirow{3}{*}{ Contrast pans of the mixed compartment } & \multicolumn{2}{|c|}{ DR (Mabenje/Tinde3) } & 0 & {$[0 ; 0]$} \\
\hline & \multicolumn{2}{|l|}{ DR (Mabale/Tinde3) } & 0.04 & {$[0.015 ; 0.12]$} \\
\hline & \multicolumn{2}{|l|}{ DR (Mataka/Tinde3) } & 0 & {$[0 ; 0]$} \\
\hline \multirow[t]{4}{*}{ Contrast pans of the national park compartment } & \multicolumn{2}{|l|}{ DR (Nyam/Tinde3) } & 0.01 & {$[0.001 ; 0.09]$} \\
\hline & \multicolumn{2}{|l|}{ DR (Guvalala/Tinde3) } & 0.13 & {$[0.05 ; 0.36]$} \\
\hline & \multicolumn{2}{|l|}{ DR (Makwa/Tinde3) } & 0 & {$[0 ; 0]$} \\
\hline & \multicolumn{2}{|l|}{ DR (Bala_bala/Tinde3) } & 0 & {$[0 ; 0]$} \\
\hline \multirow[t]{2}{*}{ Contrast pans of the communal compartment } & \multicolumn{2}{|l|}{ DR (Tinde1/Tinde3) } & 1.95 & {$[1.32 ; 2.89]$} \\
\hline & \multicolumn{2}{|l|}{ DR (Tinde2/Tinde3) } & 3.35 & {$[1.83 ; 6.15]$} \\
\hline \multirow[t]{4}{*}{ Contrast vegetation types } & \multicolumn{2}{|l|}{ DR (Grass-Bush/Grass) } & 0.91 & {$[0.38 ; 2.21]$} \\
\hline & \multicolumn{2}{|l|}{ DR (Grass-Wood/Grass) } & 0.10 & {$[0.03 ; 0.33]$} \\
\hline & \multicolumn{2}{|l|}{ DR (Grass-Bush-Wood/Grass) } & 0.23 & {$[0.08 ; 0.68]$} \\
\hline & \multicolumn{2}{|l|}{ DR (Bush/Grass) } & 1.16 & {$[0.46 ; 2.92]$} \\
\hline Contrast distance to water & \multicolumn{2}{|l|}{$\mathrm{DR}(0-50 \mathrm{~m} / 50-100 \mathrm{~m})$} & 1.89 & {$[1.44 ; 2.50]$} \\
\hline
\end{tabular}

Note: contrast parameters are expressed in terms of odd ratios (OR) for detection parameters and in terms of Density Ratios (DR) for density parameters

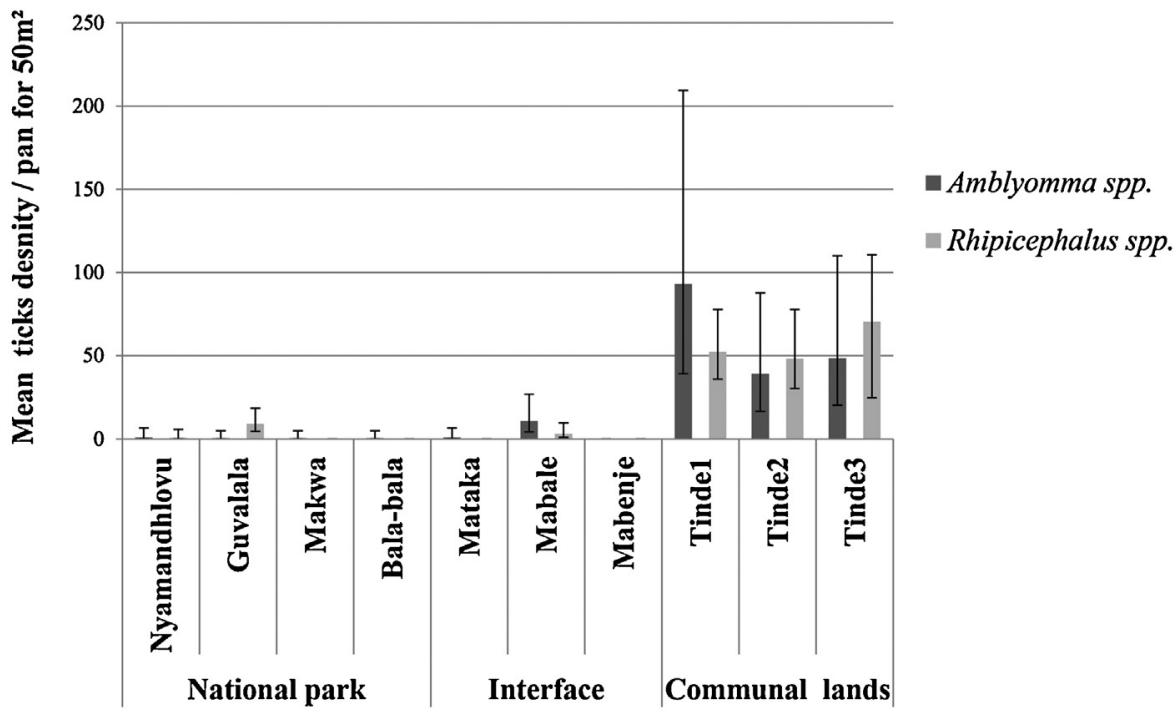

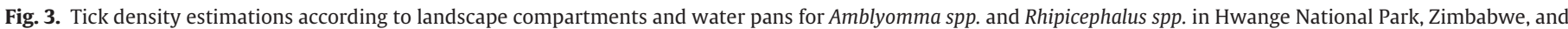
its periphery, at the end of the rainy season (between March and April) 2011. 
Table 4

Amblyomma spp.: Modelling of detection probability and density.

\begin{tabular}{|c|c|c|c|c|}
\hline \multicolumn{5}{|l|}{ a) Model selection } \\
\hline Density (with intercept) & Detection (with intercept) & AIC & Delta AIC & no. Par. \\
\hline Pan + Dist to water & AM/PM + One way & 1519.97 & 0.00 & 14 \\
\hline Pan + Dist to water & AM/PM + Forth/Back + Band & 1521.37 & 1.40 & 15 \\
\hline Pan & $\mathrm{AM} / \mathrm{PM}+$ Forth/Back & 1550.86 & 30.89 & 13 \\
\hline Pan & AM/PM + Forth/Back + Band & 1552.43 & 32.46 & 14 \\
\hline Pan & $\mathrm{AM} / \mathrm{PM}$ & 1557.07 & 37.10 & 12 \\
\hline Compartment + Dist to water & $\mathrm{AM} / \mathrm{PM}+$ Forth/Back & 1571.99 & 52.02 & 7 \\
\hline Compartment & $\mathrm{AM} / \mathrm{PM}+$ Forth/Back + Band & 1602.44 & 82.47 & 7 \\
\hline Compartment & $\mathrm{AM} / \mathrm{PM}$ & 1606.78 & 86.81 & 5 \\
\hline Pan + Dist to water & Constant & 1648.31 & 128.34 & 12 \\
\hline Vegetation & $\mathrm{AM} / \mathrm{PM}$ & 1817.16 & 297.19 & 7 \\
\hline Pan + Vegetation & $\mathrm{AM} / \mathrm{PM}$ & 1971.62 & 451.65 & 16 \\
\hline Dist to water & $\mathrm{AM} / \mathrm{PM}$ & 2044.45 & 524.48 & 4 \\
\hline Direction & $\mathrm{AM} / \mathrm{PM}$ & 2045.55 & 525.58 & 6 \\
\hline Constant & AM/PM + Forth/Back + Band & 2063.37 & 543.40 & 5 \\
\hline Constant & Constant & 2128.46 & 608.49 & 2 \\
\hline Dipping & $\mathrm{AM} / \mathrm{PM}$ & 2142.38 & 622.41 & 4 \\
\hline \multicolumn{5}{|l|}{ b) Estimates Amblyomma spp. } \\
\hline Amblyomma spp. & \multicolumn{2}{|l|}{ Parameter } & Estimate & Std. error \\
\hline preference (PM, way back) & \multicolumn{2}{|l|}{$p$} & 0.02 & {$[0.01 ; 0.05]$} \\
\hline Contrast AM & \multicolumn{2}{|l|}{$\mathrm{OR}(\mathrm{AM} / \mathrm{PM})$} & 0.42 & {$[0.33 ; 0.54]$} \\
\hline Contrast forth/back & \multicolumn{2}{|l|}{ OR(forth/back) } & 1.36 & {$[1.10 ; 1.69]$} \\
\hline$\lambda$ reference (Tinde 3 , dist water $50-100 \mathrm{~m}$ ) & \multicolumn{2}{|c|}{ Lambda (mean number of ticks on a $50 \mathrm{~m}^{2}$ transect) } & 35.46 & {$[14.25 ; 73.94]$} \\
\hline \multirow[t]{3}{*}{ Contrast pans of the mixed compartment } & DR (Mabenje/Ti & & 0 & {$[0 ; 0]$} \\
\hline & DR (Mabale/Tin & & 0.22 & {$[0.13 ; 0.38]$} \\
\hline & DR (Mataka/Tin & & 0.02 & {$[0.003 ; 0.11]$} \\
\hline Contrast pans of the national park compartment & DR (Nyam/Tind & & 0.02 & {$[0.003 ; 0.11]$} \\
\hline & DR (Guvalala/Ti & & 0.01 & {$[0.002 ; 0.09]$} \\
\hline & DR (Makwa/Tin & & 0.01 & {$[0.002 ; 0.09]$} \\
\hline & DR (Bala_bala/T & & 0.01 & {$[0.002 ; 0.09]$} \\
\hline Contrast pans of the communal compartment & DR (Tinde1/Tinc & & 1.92 & {$[1.46 ; 2.52]$} \\
\hline & DR (Tinde2/Tin & & 0.81 & {$[0.58 ; 1.13]$} \\
\hline Contrast distance to water & $\mathrm{DR}(0-50 \mathrm{~m} / 50$ & & 1.99 & {$[1.58 ; 2.52]$} \\
\hline
\end{tabular}

Note: contrast parameters are expressed in terms of odd ratios (OR) for detection probability parameters and in terms of Density Ratios (DR) for density parameters

\subsection{Rhipicephalus spp. and Amblyomma spp. density}

The models selected for both Rhipicephalus spp. and Amblyomma spp. (Tables 3a and 4a) included the effects of pan on density. For Rhipicephalus spp. only, the effect of vegetation type on density was also included in the selected model. Tick density varied among pans (Tables 3a and 4a) with higher densities found at pans located in the communal land, estimated around 60 ticks $/ 50 \mathrm{~m}^{2}$ for Amblyomma spp. and 54 ticks $/ 50 \mathrm{~m}^{2}$ for Rhipicephalus spp., as compared to pans located in other landscape compartments: around 11 ticks $/ 50 \mathrm{~m}^{2}$ for Amblyomma spp. and 3 ticks $/ 50 \mathrm{~m}^{2}$ for Rhipicephalus spp. in the mixed compartment, and 0 ticks $/ 50 \mathrm{~m}^{2}$ for Amblyomma spp. and 9 ticks $/ 50 \mathrm{~m}^{2}$ for Rhipicephalus spp. in the national park (Tables 3b and 4b and Fig. 3 for pan specific estimations and their standard errors). Density also varied according to the distance to the water body: it was higher on blocks close to the water body $(0-50 \mathrm{~m})$ than on blocks further away. Finally, for Rhipicephalus spp., density varied according to the vegetation type, being higher in grassland and bushland than in woodland vegetation types.

\subsubsection{Relationship between hosts diversity and tick density}

Host Shannon index was lower in the communal lands, where tick density estimations were high, than in the mixed compartment and national park where tick density estimations were low (Fig. 4).

\section{Discussion}

Studying vector abundance in multi-host systems occupying heterogeneous landscapes is an important step for the assessment of the risk of pathogen spillover between wild and domestic

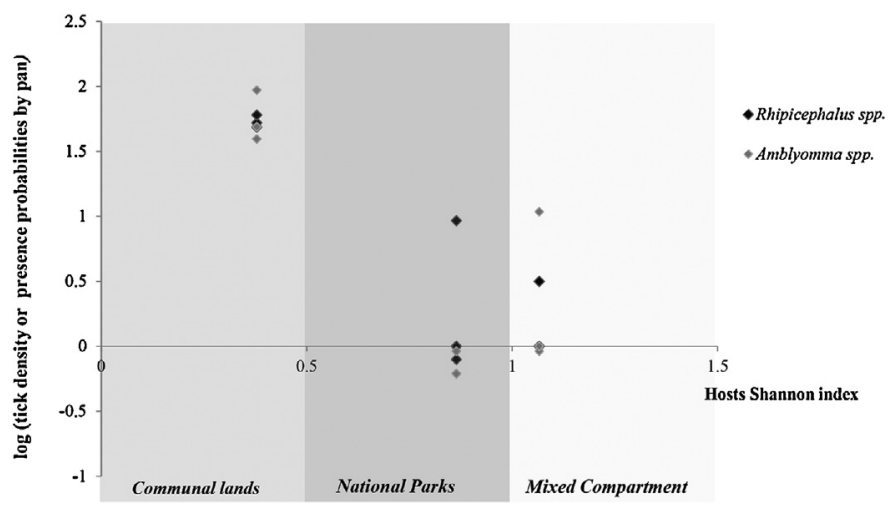

Fig. 4. Tick density estimations at the end of the rainy season for the 2 tick genus as a function of the hosts Shannon index for large vertebrate host species in the different landscape compartments (i.e. Communal lands, National park and Mixed Compartment).

animals (Power and Mitchell, 2004). Vector abundance measurements in landscape compartments used with different intensity by wild and domestic hosts is one of the first descriptive steps to depict such systems. In our study, conducted in a structured landscape including areas used only by wild ungulates, areas used only by domesticated ungulates and areas used by both, we aimed at depicting the pattern of spatial variation in the density of immature ticks.

However, in such investigations, sound statistical inference can be hampered by a number of biological and perception issues that, if ignored, could lead to distorted representations of density variation 
patterns (Randolph and Dobson, 2012; Schulze et al., 1997). Two such issues are low and variable individual detection probabilities and aggregated spatial distributions. To address these issues, we used a hierarchical (multi-level) repeated tick sampling protocol and analysed the resulting data with generalized linear mixed models and site occupancy models. Up to date, it is the first utilization of these rigorous sampling and statistical modelling methodologies to estimate tick abundance in African ecosystem simultaneously at large (i.e. landscape compartment characterized by contrasted host community) and small (i.e. water pan) spatial scales.

\subsection{Small scale variation in tick density or presence}

The interaction between adult ticks, their hosts and the environment influences the abundance and the spatial distribution of free living immature ticks (Minshull and Norval, 1982). Here, we found that the densities of Amblyomma spp. and Rhipicephalus spp. were higher close to water $(0-50 \mathrm{~m})$ than further away (50-100 m). This result is similar to the findings of other tick surveys carried out in Zimbabwe, concluding that immature ticks were not homogenously distributed across the landscape (De Garine-Wichatitsky et al., 1999; Minshull, 1981). Two explanations may be put forward, related to the spatial behavior of the preferred hosts of the adult ticks, or related to the survival of the immature stages. First, this pattern could arise because hosts often remain close to the water body before and/or after they use the water pans for drinking (Valeix et al., 2007a). In the study area, ungulate hosts are the preferred hosts for adult stages of the most abundant species of Amblyomma spp. (i.e. A. hebraeum and A. variegatum; (Norval et al., 1994)) and Rhipicephalus spp. (i.e. R. evertsi, R. appendiculatus, R. (Boophilus) decoloratus; (Mason and Norval, 1980; Norval, $1981,1982)$ ). As the dispersion range of tick larvae from the dropping site of engorged adult female after they detach from their hosts is very limited (Rechav, 1979), habitat preference of the hosts favouring the vicinity of water pans could result in higher densities of immature ticks close to water holes (De Garine-Wichatitsky et al., 1999). Another potential explanation could be that the survival of free-living immature ticks is higher close to water pans compared to other habitats located further from water. Although African ticks have been shown to be relatively resistant to desiccation, higher humidity increases the survival of free-living immature stages depending on the species considered (Short et al., 1989), which could result in higher densities close to water.

\subsection{Large scale variation in tick density or presence among landscape compartments}

We found a clear and similar distribution pattern for the three tick genus detected during our study. Tick presence and density were much higher around water pans located in the communal landscape compartment as compared to water pans located in protected or mixed compartments. This result suggests that tick distribution is highly unbalanced across landscape compartments at that interface between conservation and communal lands. It also suggests that the risk of transmission of tick borne diseases is much higher among domestic hosts than among wild hosts as well as than between wild and domestic hosts. However, this pattern was unexpected for at least two reasons: first, host density (for ungulates) does not differ greatly among compartments in our system where farming activities are extensive; second, the tick hosts occupying the communal compartment are domestic ungulates that are regularly treated against ticks at diptanks. We suggest below potential explanations for this unexpected pattern.

\subsubsection{Water availability}

One factor that could shed light on the density pattern revealed by our study is the permanence and distribution of water pans. The frequency at which water pans dry out during the dry season could differ among the landscape compartments. A higher drying out frequency in the national park and mixed compartment than in the communal lands could result in a more continuous host frequentation in this later area. Another interpretation related to water availability and host frequentation could be that during the rainy season the increase in the number of water pans available to free moving wild ungulates is larger than the increase in the number of water points used by domestic animals, for which movements are restricted to a much smaller area (Miguel et al., 2013), with fewer water pans available. As a consequence, the frequentation by wild ungulates of some water pans in the protected area might decrease during the rainy season while water point frequentation by domestic ungulates in the communal lands may remain constant throughout the year. Because we presently lack precise information on seasonal variation in water distribution in the different landscape compartments, these interpretations are for the time being speculative. However, we believe that water pan distribution and dynamics could influence frequentation by tick hosts and thus also tick densities. Variations in water availability may also affect directly the survival of ticks in the environment (Randolph and Storey, 1999).

\subsubsection{Host diversity and availability}

Our results are also compatible with the "dilution effect" hypothesis (Schmidt and Ostfeld, 2001) which states that a highly diversified host system, including hosts on which tick survival and reproductive success are highly variable, could decrease the density of tick populations as compared to a less diversified host system only composed of hosts on which tick survival and reproductive success are homogeneously high (Keesing et al., 2006, Roche and Guegan, 2011). Indeed, host diversity as quantified using the Shannon index is higher in the protected and mixed compartments than in the communal compartment (Fig. 4). Although the "dilution effect" has been elaborated for explaining variation related to the composition of host communities in the prevalence of pathogenic micro-parasites such as the Borrelia bacteria causing the Lyme disease (Schmidt and Ostfeld, 2001) or the virus causing the West Nile disease (Swaddle and Calos, 2008), it could also apply to macroparasites such as ticks (Krasnov et al., 2007). However, tick survival and reproductive success on African wild hosts are currently poorly documented in the literature. Without such information it is difficult to evaluate the relevance of the dilution effect hypothesis in the present study (Randolph and Dobson, 2012).

The tick density pattern revealed in the present study should also be considered in the light of variation in the density of hosts for immature (i.e. larval and nymphal) tick stages. For several tick species, ground frequenting bird (e.g. for Amblyomma variegatum) and small mammals such as gerbils or hares (e.g. for Hyalomma truncatum) are the hosts of immature ticks. Communal lands which are characterized by a mosaic of anthropic land types (e.g. fields, homesteads), some of which can be rich in terms of resources (e.g. crops), could constitute for some of these hosts a more favourable habitat than protected areas.

\subsection{Sampling ticks appropriately and methodological issues}

Repeated sampling is generally an efficient solution to estimate detection probabilities and integrate the detection process in the estimation of abundance or occupancy probabilities (Mackenzie and Royle, 2005). However, in the specific situation of tick sampling by the flag dragging technique, the issue of removal arises (Kramer et al., 1993). Indeed, with this sampling technique, the 
ticks detected at a given sampling replicate are removed from the tick population and are no longer available for detection at subsequent sampling replicates of the same site (Falco and Fish, 1992; Talleklint-Eisen and Lane, 2000). Such removal of sampled ticks results in a departure from the closed population assumption, because the size of the population that can potentially be detected decreases with successive sampling replicates of a same sampling unit. We accounted for this by including the effects of time of the day and dragging direction (back/forth) in the detection part of the occupancy and abundance models. And indeed, site occupancy modelling of Amblyomma spp. and Rhipicephalus spp., showed a significant effect of sampling order, with lower detection probabilities on the back sampling replicates. Ideally, one would explicitly specify in a statistical model that the number of individuals available for detection at a given sampling replicate on a given track is the number of individuals available for detection on that track before the first sampling replicate minus the sum of those detected, and thus removed, at sampling replicates undertaken before the focal sampling replicate. However, the development of such models has so far, to our knowledge, not been attempted, and is beyond the scope of the present paper. An alternative solution to account for the removal effect would be to aggregate the data of the four replicate of a same track (i.e. to sum the number of ticks detected on the forth and back replicates of the morning and afternoon sessions of a track) and consider the resulting data as the outcome of a single sampling replicate of the block in which the transect is located. On the one hand, this option would solve the removal effect issue. On the other hand, however, this option would result in a reduction in the number of sampling replicates for each block (4[tracks] replicates instead of 4 [tracks] $\times 2$ [morning/afternoon] $\times 2$ [forth/back] replicates) and would thus potentially impair our ability to disentangle density variation and variation in individual detection probability.

Modelling of the number of detected ticks with generalized linear mixed models allowed us to assess aggregation of ticks at different spatial scale. It revealed, for the three tick genus, large variance among transects within a site (i.e. block) in the number of ticks detected. This result suggests a highly clumped distribution of ticks within areas of a few hundred meter square around water pans, which is compatible with the reproductive biology of ticks, as large numbers of tick larvae often cluster on grass stems located close to egg hatching sites (Londt and Whitehead, 1972). Such clumped distributions imply that tick abundances on $50 \mathrm{~m}^{2}$ transects probably do not follow the Poisson distribution used in the Royle and Nichols model implemented in PRESENCE. Negative binomial distributions would probably be better adapted.

\section{Conclusion}

From a methodological point of view, we believe that repeated density sampling combined with models that depict explicitly variation in detection probability along with variation in density are an efficient method to accurately estimate tick distribution. They are particularly adapted to situations where the efficiency of sampling methods varies among tick species or stages. Indeed, because with these methods the detection probabilities are estimated and their variations are modeled, they are likely to produce estimations of density and presence probability that are comparable among species and stages. However, models that account for the removal of detected ticks and that allow the use of negative binomial distribution to deal with aggregation should be developed.

From a biological point of view, because tick density seems much higher in the communal lands than in the national park and mixed compartment, we would expect tick borne diseases to have higher transmission rates among domesticated ungulates in the communal lands than among wild ungulates in the national park or between wild and domestic ungulates in the mixed compartment. The spatial tick distribution pattern revealed in our study with higher tick densities in the compartment characterized by the lowest host diversity is relevant to the debate on the role of biodiversity in the limitation and regulation of parasites and pathogens populations. More extended epidemiological surveys are now needed to explore in more details the relationships between vector density, infectious risk and host density and diversity.

\section{Acknowledgements}

We thank the National Park(NP) services of Zimbabwe for allowing us to carry our study within Hwange NP, and Government Veterinary Services assistance and access to livestock statistics. We also thank Juliette Banda, Chiswa, Cavin Mandina, Billy Butete, Lovemore Kameva and all the field assistants for their help at various stages of the work. The project was conducted within the framework of the Research Platform "Production and Conservation in Partnership" (RP-PCP). It was funded by Cirad, the French Ministry of Foreign Affairs (Harare, SCAC funds 2009-2012) and the French ANR (FEAR project ANR-08-BLAN-0022).

\section{References}

Anderson, J.A., De Garine-Wichatitsky, M., Cumming, D.H.M., Dzingirai, V., Giller, K.E., 2012. Transfrontier conservation areas: people living on the edge. Routledge.

Bailey, L.L., Simons, T.R., Pollock, K.H., 2004. Estimating site occupancy and species detection probability parameters for terrestrial salamanders. Ecol. Appl. 14 (3), 692-702.

Baudron, F., Corbeels, M., Andersson, J.A., Sibanda, M., Giller, K.E., 2011. Delineating the drivers of waning wildlife habitat: the predominance of cotton farming on the fringe of protected areas in the Mid-Zambezi Valley, Zimbabwe. Biol. Conserv. 144, 1481-1493.

Boulinier, T., Ives, A.R., Danchin, E., 1996. Measuring aggregation of parasites at different host population levels. Parasitology 112, 581-587.

Burnham, K.P., Anderson, D.R., 2002. Model selection and multimodel inference: a practical information-theoretic approach. Springer Verlag, New York, USA.

Butler, J.R.A., 2000. The economic costs of wildlife predation on livestock in Gokwe communal land, Zimbabwe. Afr. J. Ecol. 38, 23-30.

Caron, A., Miguel, E., Gomo, C., Makaya, P., Pfukenyi, D.M., Foggin, C., Hove, T., de Garine-Wichatitsky, M., 2013. Relationship between burden of infection in ungulate populations and wildlife/livestock interfaces. Epidemiol. Infect. 141, $1522-1535$

Chamaille-Jammes, S., Valeix, M., Bourgarel, M., Murindagomo, F., Fritz, H., 2009. Seasonal density estimates of common large herbivores in Hwange National Park, Zimbabwe. Afr. J. Ecol. 47, 804-808.

De Garine-Wichatitsky, M., De Meeus, T., Guegan, J.F., Renaud, F., 1999. Spatial and temporal distributions of parasites: can wild and domestic ungulates avoid African tick larvae? Parasitology 119, 455-466

Elston, D.A., Moss, R., Boulinier, T., Arrowsmith, C., Lambin, X., 2001. Analysis of aggregation, a worked example: numbers of ticks on red grouse chicks. Parasitology 122, 563-569.

Falco, R.C., Fish, D., 1992. A comparison of methods for sampling the deer tick, ixodesdammini, in a lyme-disease endemic area. Exp. Appl. Acarol. 14, 165-173.

Gibbs, H.K., Ruesch, A.S., Achard, F., Clayton, M.K., Holmgren, P., Ramankutty, N., Foley, J.A., 2010. Tropical forests were the primary sources of new agricultural land in the 1980 and 1990. Proc. Natl. Acad. Sci. 107, 16732-16737.

Green, R.E., Cornell, S.J., Scharlemann, J.P., Balmford, A., 2005. Farming and the fate of wild nature. Science 307, 550-555.

Guerbois, C., Chapanda, E., Fritz, H., 2012. Combining multi-scale socio-ecological approaches to understand the susceptibility of subsistence farmers to elephant crop raiding on the edge of a protected area. J. Appl. Ecol. 49, 1149-1158.

Hails, R.S., Ormerod, S.J., 2013. Editorial: Ecological science for ecosystem services and the stewardship of Natural Capital. J. Appl. Ecol. 50, 807-811.

Hines, J.E., 2006. PRESENCE - Software to estimate patch occupancy and related parameters. USGS-PWRC, in: http://www.mbr-pwrc.usgs.gov/software/ presence.htlm. (Ed.)

Jones, B.A., Grace, D., Kock, R., Alonso, S., Rushton, J., Said, M.Y., McKeever, D., Mutua, F., Young, J., McDermott, J., Pfeiffer, D.U., 2013. Zoonosis emergence linked to agricultural intensification and environmental change. Proc. Natl. Acad. Sci. 110, 8399-8404.

Keesing, F., Holt, R.D., Ostfeld, R.S., 2006. Effect of species diversity on disease risk. Ecol. Lett. 9, 485-498.

Kramer, V.L., Carper, E.R., Beesley, C., 1993. Mark and recapture of adult ixodes pacificus (acari, ixodidae) to determine the effect of repeated removal sampling on tick abundance. J. Med. Entomol. 30, 1071-1073. 
Krasnov, B.R., Stanko, M., Morand, S., 2007. Host community structure and infestation by ixodid ticks: repeatability, dilution effect and ecological specialization. Oecologia 154, 185-194.

Latif, A.A., Hove, T., Kanhai, G.K., Masaka, S., 2002. Buffalo-associated Theileria parva: the risk to cattle of buffalo translocation into the Highveld of Zimbabwe. Ann. NY Acad. Sci. 969, 275-279.

Logiudice, K., Duerr, S.T.K., Newhouse, M.J., Schmidt, K.A., Killilea, M.E., Ostfeld, R.S., 2008. Impact of host community composition on lyme disease risk. Ecology 89, 2841-2849

Londt, J.G.H., Whitehead, J.B., 1972. Ecological studies of larval ticks in South Africa (Acarina: Ixodidae). Parasitology, 469-490.

Lyashevska, O., Farnsworth, K.D., 2012. How many dimensions of biodiversity do we need? Ecol. Indic. 18, 485-492.

MacKenzie, D.I., 2005. What are the issues with presence-absence data for wildlife managers? J. Wildlife Manage. 69, 849-860.

Mackenzie, Royle, 2005. Designing occupancy studies: general advice and allocating survey effort. J. Appl. Ecol. 42, 1105-1114.

Mason, C.A., Norval, R.A.I., 1980. The ticks of Zimbabwe. I. The genus Boophilus. Zimbabwe Vet. J., 36-43.

McClintock, B.T., Nichols, J.D., Bailey, L.L., MacKenzie, D.J., Kendall, W.L., Franklin, A.B., 2010. Seeking a second opinion: uncertainty in disease ecology. Ecol. Lett.

Miguel, E., Grosbois, V., Caron, A., Boulinier, T., Fritz, H., Cornélis, D., Foggin, C. Makaya, P.V., Tshabalala, P.T., de Garine-Wichatitsky, M., 2013. Contacts and foot and mouth disease transmission from wild to domestic bovines in Africa. Ecosphere 4, art51.

Minshull, J.I., 1981. Seasonal occurence, habitat distribution and host range of four ixodid ticks species at Kyle recreational park in south eastern Zimbabwe. Zimbabwe Vet. J., 58-63.

Minshull, J.I., Norval, R.A.I., 1982. Factors influencing the spatial distribution of Rhipicephalus appendiculatus in Kyle Recreational Park, Zimbabwe. S. Afr. J. Wildl. Res., 118-123.

Norval, R.A., Perry, B.D., Young, A.S., 1992. The epidemiology of Theileriosis in Africa. Academic Press.

Norval, R.A., Perry, B.D., Meltzer, M.I., Kruska, R.L., Booth, T.H., 1994. Factors affecting the distributions of the ticks Amblyomma hebraeum and A. variegatum in Zimbabwe: implications of reduced acaricide usage. Exp. Appl. Acarol. 18, 383-407.

Norval, R.A.I., 1981. The ticks of Zimbabwe III. Rhipicephalus evertsi evertsi. Zimbabwe Vet. J., 31-35.

Norval, R.A.I., 1982. The ticks of Zimbabwe. IV. The genus Hyalomma. Zimbabwe Vet. J., 2-10.

Petney, T.N., Spickett, A.M., Van Ark, H., 1990. On sampling tick populations: the problem of overdispersion. Onderstepoort J. Vet. Res. 57, 123-127.

Power, A.G., Mitchell, C.E., 2004. Pathogen spillover in disease epidemics. Am. Nat. 164 (Suppl 5), S79L 89

Randolph, S.E., Dobson, A.D.M., 2012. Pangloss revisited: a critique of the dilution effect and the biodiversity-buffers-disease paradigm. Parasitology 139, 847-863.

Randolph, S.E., Storey, K., 1999. Impact of microclimate on immature tick-rodent host interactions (Acari: Ixodidae): implications for parasite transmission. J. Med. Entomol. 36, 741-748.

Rechav, Y., 1979. Migration and dispersal patterns of three African ticks (Acari: Ixodidae) under field conditions. J. Med. Entomol., 150-163.
Restif, O., Hayman, D.T.S., Pulliam, J.R.C., Plowright, R.K., George, D.B., Luis, A.D., Cunningham, A.A., Bowen, R.A., Fooks, A.R., O'Shea, T.J., Wood, J.L.N., Webb, C.T., 2012. Model-guided fieldwork: practical guidelines for multidisciplinary research on wildlife ecological and epidemiological dynamics. Ecol. Lett. 15, 1461 2248.

Roche, B., Guegan, J.F., 2011. Ecosystem dynamics, biological diversity and emerging infectious diseases. Comptes rendus biologies 334, 385-392.

Rogers, C.M.L., 1993. A woody vegetation survey of Hwange National Park. Report Department of National Parks and Wildlife Management, Harare, Zimbabwe.

Royle, J.A., Nichols, J.D., Kéry, M., 2005. Modelling occurrence and abundance of species when detection is imperfect. oikos 110, 353-359.

Schmidt, K.A., Ostfeld, R.S., 2001. Biodiversity and the dilution effect in disease ecology. Ecology 82, 609-619.

Schulze, T.L., Jordan, R.A., Hung, R.W., 1997. Biases associated with several sampling methods used to estimate abundance of Ixodes scapularis and Amblyomma americanum (Acari: Ixodidae). J. Med. Entomol. 34, 615-623.

Short, N.J., Floyd, R.B., Norval, R.A.I., Sutherst, R.W., 1989. Development rates, fecundity and survival of developmental stages of the ticks Rhipicephalus appendiculatus, Boophilus decoloratus and B. microplus under field conditions in Zimbabwe. Exp. Appl. Acarol., 123-141.

Short, N.J., Norval, R.A.I., 1981. Regulation of seasonal occurence in the tick Rhipicephalus appendiculatus Neumann 1901. Trop. Anim. Health Pro. 13, 19-26.

Spickett, A.M., Horak, I.G., Heyne, H., Braack, L.E.O., 1995. The effect of severe drough on the abundance of ticks on vegetation and on scrub hares in the Kruge National Park. Koedoe, 59-64.

Swaddle, J.P., Calos, S.E., 2008. Increased avian diversity is associated with lower incidence of human West Nilr infections: observation of the dilution effect. Plos One 3, e2488.

Talleklint-Eisen, L., Lane, R.S., 2000. Efficiency of drag sampling for estimating population sizes of Ixodes pacificus (Acari: Ixodidae) nymphs in leaf litter. J. Med. Entomol. 37, 484-487.

Uilenberg, G., Dobbelaere, D.A.E., Degee, A.L.W., Koch, H.T., 1993. Progress in research on tick-borne diseases - Theileriosis and Heartwater. Vet. Quart. 15, 48-54.

Valeix, M., 2011. Temporal dynamics of dry-season water-hole use by large African herbivores in two years of contrasting rainfall in Hwange National Park, Zimbabwe. J. Trop. Ecol. 27, 163-170.

Valeix, M., Chamaille-Jammes, S., Fritz, H., 2007a. Interference competition and temporal niche shifts: elephants and herbivore communities at waterholes. Oecologia 153, 739-748.

Valeix, M., Fritz, H., Dubois, S., Kanengoni, K., Alleaume, S., Said, S., 2007b. Vegetation structure and ungulate abundance over a period of increasing elephant abundance in Hwange National Park, Zimbabwe. J. Trop. Ecol. 23, 87-93.

Walker, A.R., Bouattour, A., Camicas, J.-L., Estrada-Pena, A., Horak, I.G., Latif, A.A Horak, I.G., Latif, A.A., 2007. Vegetation structure and ungulate abundance over a period of increasing elephant abundance in Hwange National Park, Zimbabwe. J. Trop. Ecol. 23, 87-93.

Wittemyer, G., Elsen, P., Bean, W.T., Burton, A.C.O., Brashares, J.S., 2008. Accelerated human population growth at protected area edges. Science 321, 123126.

Zengeya, F., Murwira, A., de Garine-Wichatitsky, M., 2011. An IKONOS-based comparison of methods to estimate cattle home ranges in a semi-arid landscape of southern Africa. Int. J. Remote Sens. 32, 7805-7826. 